DOI: 10.15393/j9.art.2019.6422

УДК 821.161.1.09“18”

И. А. Киселева

Московский государственный областной университет

(Москва, Российская Федерация)

79099227849@yandex.ru

\title{
О смысловой цельности дефинитивного текста поэмы М. Ю. Лермонтова «Демон» (1839)
}

Аннотация. Предметом исследования являются отдельные аспекты творческой истории поэмы М. Ю. Лермонтова «Демон» в их соответствии целостному замыслу. В центре внимания песня Демона «Лишь только ночь своим покровом...», портрет Тамары в 6-й и 8-й редакциях, эпизод спасения ее души. Стихотворение «Когда волнуется желтеющая нива...» (1837) рассматривается как контрастная аллюзия к обольщающей песне Демона. Божие всеприсутствие в стихотворении противопоставляется условности и ограниченности бытия и обещаний Демона. Сопоставление песни Демона со стихотворением позволяет вскрыть художественную и смысловую противоречивость редакции 1838 г. (6-й) по сравнению с редакцией 1839 г. (8-й). Появившаяся в 6-й редакции песня Демона потребовала изменения развязки сюжета, которое и было предложено в 8-й редакции. Изменение развязки определило принципиальное отличие портрета Тамары в 8-й редакции по сравнению с 6-й. Страстность героини сменяется изображением младенческой души, красота которой выражается в являющем образ тварного совершенства земном облике Тамары. Привлекаемое для анализа поэмы «Демон» стихотворение М. Ю. Лермонтова "Ангел» (1831), перифраза которого наиболее явно прослеживается в развязке 8-й редакции, рассматривается как часть замысла поэмы. Делается вывод о том, что именно 8-я редакция целостно и непротиворечиво отражает миросозерцание М. Ю. Лермонтова, веру поэта во всеблагость Творца и в высшую разумность мироздания.

Ключевые слова: Лермонтов, «Демон», «Ангел», редакции, текстология, ангел, архитектоника текста, духовная реальность, портрет Тамары

Об авторе: Киселева Ирина Александровна - доктор филологических наук, профессор, зав. кафедрой русской классической литературы, Московский государственный областной университет (ул. Фридриха Энгельса, д. 21, стр. 3, г. Москва, Российская Федерация, 105005)

Дата поступления: 15.01.2019

Дата публикации: 18.10.2019

Для цитирования: Киселева И. А. О смысловой цельности дефинитивного текста поэмы М. Ю. Лермонтова «Демон» (1839) // Проблемы исторической поэтики. - 2019. - Т. 17. — № 4. - C. 91-106. DOI: 10.15393/j9. art.2019.6422

(с) И. А. Киселева, 2019 
П ервое издание поэмы М. Ю. Лермонтова «Демон» было 1 предпринято А. И. Философовым в 1856 г. в Германии, в г. Карлсруэ, в количестве всего 28 экземпляров. Это издание в текстологическом отношении можно считать наиболее соответствующим авторской воле, так как оно было точно переписано издателем в 1841 г. с утраченного позже автографа Лермонтова. Начиная с 1935 г. издателями за основную берется 8-я редакция поэмы, в которую, однако, включаются, хотя и с оговорками, в скобках, элементы 6-й редакции (в частности, диалог Тамары с Демоном «Зачем мне знать твои печали...»).

Однако споры вокруг выбора дефинитивного текста поэмы Лермонтова «Демон» велись вплоть до конца 1970-х гг. ${ }^{1}$ Предмет дискуссии в своей основе был связан с художественными достоинствами произведения, авторской волей и проблемой получения автором цензурного разрешения на издание поэмы. Полемику советского периода вокруг выбора дефинитивного текста хорошо отражает статья А. М. Докусова, который, отстаивая в открытом диалоге с Т. А. Ивановой [Иванова: 314] и Д. А. Гиреевым [Гиреев: 157-159] независимость содержания 8-ой редакции «Демона» от цензурных соображений, убедительно доказывал, что «основным источником текста поэмы должна быть найденная А. Михайловой [Михайлова: 1948] в архиве Философовых писарская копия, с которой производился набор издания 1856 г.» [Докусов: 121]. Этапной в вопросе выбора основной редакции является статья Э. Э. Найдича, который на основании обнаруженного им письма А. И. Философова к М. А. Корфу о первом издании поэмы не только аргументирует выбор текста 8-й редакции поэмы «Демон» как основного, но доказательно утверждает, что «последняя редакция “Демона” написана не позднее февраля 1839 г.» [Найдич: 78], а не в 1841 г., как считалось ранее. Наконец, обоснованный довод в пользу последней редакции представил В. Э. Вацуро в 1979 г. посредством своей находки цензурного разрешения 8-й редакции. Исследователь утверждал, что «в марте 1839 г. Лермонтов считал поэму оконченной и готовил ее к опубликованию» [Вацуро: 414]. Однако уже в 1973 г. Б. В. Удодов заявил, что на сегодняшний момент вопрос о выборе основной редакции решен и главная сложность состоит «не в выборе текста, а в правильном истолковании его во многом загадочного смысла» [Удодов: 244]. 
Несмотря на выделенные восемь редакций поэмы, над которой Лермонтов работал с 1829 по 1839 г., научные дискуссии, связанные с публикацией поэмы, ее художественной и философской значимостью, посвящены только двум редакциям, так как только редакции 1838 г. $^{2}$ (6-я ред.) и 1839 г. $^{3}$ (8-я ред.) можно считать законченными, но значительно разнящимися по своему сюжетному решению текстами. При существенных смысловых разночтениях общими остаются мотивы (в том числе ведущие - мотив искушения души падшим духом и мотив спасения) и достаточно большой пласт текстового материала, который не связан напрямую с завязкой, кульминацией и развязкой. Объектом настоящего исследования стали части 6-й и 8-й редакций «Демона», в частности одна из песен Демона, портрет героини и стихи, появляющиеся только в 8-й редакции и связанные с изображением полета ангела, несущего душу Тамары.

Песня Демона «Лишь только ночь своим покровом...» появляется в лермонтовской поэме только в 1838 г. (6-я ред.) и переходит почти без изменений (за исключением стиха «долины ваши осенит» ${ }^{4}$ в 6-й ред. вместо «верхи Кавказа осенит» в 8-й ред.) в окончательную редакцию 1839 г.:

«Лишь только ночь своим покровом

Верхи Кавказа осенит,

Лишь только мир, волшебным словом

Завороженный, замолчит;

Лишь только ветер над скалою

Увядшей шевельнет травою, И птичка, спрятанная в ней, Порхнет во мраке веселей; И под лозою виноградной, Росу небес глотая жадно, Цветок распустится ночной; Лишь только месяц золотой Из-за горы тихонько встанет И на тебя украдкой взглянет, К тебе я стану прилетать; Гостить я буду до денницы И на шелковые ресницы Сны золотые навевать...» (IV, 194). 
Песня Демона по своей структуре представляет синтаксический период и по архитектонике соотносима со стихотворением Лермонтова 1837 г. «Когда волнуется желтеющая нива... .»:

«Когда волнуется желтеющая нива

И свежий лес шумит при звуке ветерка,

И прячется в саду малиновая слива

Под тенью сладостной зеленого листка;

Когда росой обрызганный душистой,

Румяным вечером иль в утра час златой,

Из-за куста мне ландыш серебристый

Приветливо кивает головой;

Когда студеный ключ играет по оврагу

И, погружая мысль в какой-то смутный сон,

Лепечет мне таинственную сагу

Про мирный край, откуда мчится он, -

Тогда смиряется души моей тревога,

Тогда расходятся морщины на челе, -

И счастье я могу постигнуть на земле,

И в небесах я вижу Бога...» (II, 92).

Песня Демона «Лишь только ночь своим покровом...» и стихотворение «Когда волнуется желтеющая нива...» близки по образному строю. В обоих текстах присутствуют образы ветер, флора (ландыш, слива, виноградная лоза), роса. Примечательно и то, что в редакции «Демона» 1838 г., вместо стихов «верхи Кавказа осенит» были стихи «долины ваши осенит», что еще более текстуально сближает песню Демона со стихотворением «Когда волнуется желтеющая нива...», но в меньшей степени соответствует пейзажному колориту поэмы.

В поэме «Демон» и в стихотворении «Когда волнуется желтеющая нива...» Лермонтов изображает приметы земного мира в его связи с духовной реальностью, но если в первом случае это реальность демона, то во втором - Бога. Если в песне Демона явно чувствуется ограниченность обещаний только мечтания, «сны золотые», - то в стихотворении всё существо лирического поэта вовлечено в переживаемое настоящее: «смиряется души <...> тревога», «расходятся морщины на челе». Песня Демона в ее отсылке к стихотворению «Когда волнуется желтеющая нива...» - один из важнейших 
смысловых центров произведения, образующих его «силовое поле», и определяющих «иерархию ценностей, космос (в значении упорядоченности) художественного мира поэта» [Киселева, 2013: 87].

В ходе развития сюжета Демон в одноименной поэме обещает Тамаре «пучину гордого познанья» и «все, все земное», но и в этих обещаниях нет главного - сочетания «свободы и покоя», которое, хотя и не названо прямо, но сквозит в настроении и образном строе стихотворения Лермонтова «Когда волнуется желтеющая нива...». Важно, что обещания Демона поэт презентует именно как обещания, используя синтаксическую конструкцию со значением условия. Обещания Демона иллюзорны, он способен к тому, чтобы властвовать в пределах тонкой материи - света, звука («Лучом румяного заката / Твой стан как лентой обовью» - IV, 210), но он не в состоянии быть Творцом «румяного вечера» и «утра в час златой». Демон - не творец времени, а потому его вечность это дурная бесконечность безвременья, то есть смерть физическая и духовная. Обещая Тамаре «все, все земное», Демон способен дать ей в земном лишь тленное, но не вечное. И когда в другой песне Демон провозглашает: «Будь к земному без участья» (IV, 194), то тем самым он отгораживает Тамару от реальности, в которой просвечивает небесное. И. Б. Роднянская отмечала, что поскольку представляемый Демоном мир «эфемерен» и «увековечивание в нем высших жизненных мигов иллюзорно, то попытка перемещения в несуществующий приют может разрешиться только одним: небытием, смертью, - и Тамара умирает» [Роднянская, 2006: 76].

Демон пытается отдалить Тамару от мира, а природа в его словах при всей ее временно́й реальности (ночь) приобретает характер романтической ирреальности. В стихотворении «Когда волнуется желтеющая нива...», напротив, образы природы предельно конкретны и реальны: «ландыш серебристый», «малиновая слива», овраг, по которому струится «студёный ключ».

Между двумя сторонами духовной реальности граница тончайшая, как та, что отделяет зеркальное отражение от самой действительности; и хотя в третьей строфе стихотворения «Когда волнуется желтеющая нива...» «смутный сон», 
как пишет М. Л. Гаспаров [Гаспаров, 2001: 43-55], выводит ее реальность за пределы времени, но это касается только мысли (рационального познания), тогда как бегущий по оврагу ключ остается вполне осязаемым / вещественным, но в то же время способным быть вестником духовной реальности «лепечет» «таинственную сагу» про «мирный край, откуда мчится он». Явно выраженная в четвертой строфе стихотворения реальность видения Бога при ощущении земного счастья (в которое поэт вовлечен всей полнотой своей личности) уже содержится в первых трех строфах, где изображается мир в его природном многообразии. В этих стихах перед мысленным взором поэта предстает картина, когда, выражаясь словами немецкого романтика Новалиса, «земля впитала небеса», и сам Лик Спасителя сияет «в травинке, и в морской волне»5. В стихотворении «Когда волнуется желтеющая нива...» запечатлен духовный смысл природы, который открывается именно в новозаветном образе мира, когда через воплощение Христа и его жертву природа оказывается способна к преображению и к приятию святости - освящению, поэт передает новозаветный опыт осознания единства души и тела, природы и духа (см. об этом: [Киселева, 2017: 63-64]).

Союзное слово «когда», употребленное Лермонтовым в начале стихотворения "Когда волнуется желтеющая нива...», предельно обнажает суть времени, но при этом, стоящее в начале периода, несет и утвердительный смысл, аналогичный тому, который слышится в Библии («Вначале сотворил Бог небо и землю...» - Быт. 1:1) и в «Повести временных лет» («Откуда есть пошла земля русская...»). Естественное завершение сложноподчиненного предложения в четвертой строфе («Тогда смиряется души моей тревога...»), при всей его логической обоснованности, являет собой чудо - чудо понимания смысла жизни, который заключается в созерцании Божества при ощущении полноты бытия («И счастье я могу постигнуть на земле»). Конструктивным элементом периода в поэме «Демон» является другое союзное слово - «лишь», которое наряду со значением времени имеет модальность условия, тем самым духовный модус текста снижается до ограниченности временем. 
Общим местом исследовательских работ о стихотворении «Когда волнуется желтеющая нива...» стало упоминание о том, что Лермонтов смешивает приметы различных времен года: «желтеющая нива» - конец лета в средней полосе России, тогда как «ландыш серебристый» - его начало. Если в поэме «Демон» акцентируется конкретное время суток - ночь, то временные координаты стихотворения «Когда волнуется желтеющая нива...» намеренно растянуты и характеризуются временной всеобъемлемостью: «Румяным вечером иль в утра час златой...». Эта всевременность при ощущении единого момента времени являет собой прорыв в мир горний. Пейзаж, созданный под воздействием внешних зрительных и слуховых впечатлений, становится проекцией душевного состояния поэта в его сближении с Источником красоты мира, с Богом. Мотив узрения Бога является «энергетическим центром» стихотворения [Киселева, 2011: 77]. Представленная Лермонтовым природная картина - это то самое «лето Господне благоприятное» (Ис. 61:1-3; Лк. 4: 14-20) (библейский образ, позднее использовавшийся И. А. Шмелевым), когда время входит в вечность и длится в торжестве расцвета природы. Если Демон обещает Тамаре парадоксально ограниченную «бесконечность», то в стихотворении «Когда волнуется желтеющая нива...» поэту открывается всеобъемлемость Божьего присутствия «на земле» И «в небесах». Именно опыт переживания Царствия Небесного (как раз этот образ и представляет Лермонтов в своем стихотворении) открывает читателю чистый источник жизни и вдохновения - преображенную одухотворенную природу.

Начало работы над «Демоном» относится к 1829 г., а последняя редакция - к 1839 г., тогда как песня Демона впервые появляется в редакции 1838 г., то есть после создания Лермонтовым стихотворения «Когда волнуется желтеющая нива...», и являет собой опыт распознания духовной прелести и обольщающей сути демонизма, что возможно лишь после переживания общения с Богом. «В поэтике Лермонтова, - как пишет В. Н. Захаров, - слова значат не только, а иногда не совсем то, что говорят, имеют не только прямой, но и иной, скрытый смысл высказывания» [Захаров: 25]. В данном случае скрытый смысл песни Демона вскрывается посредством вовлечения в контекст всего творчества Лермонтова. 
Исследуемые редакции (6-я и 8-я) близки текстуально, но в них есть существенные разночтения - в последней (8-й) редакции 1839 г. душа Тамары спасается, тогда как в редакции 1838 г. (6-й) Тамара остается во власти Демона. Судьба Тамары в обеих редакциях органично вытекает из сущности Тамары, однако в 6-й и 8-й редакциях значительно разнится портрет героини. Наиболее подробный портрет Тамары в анализируемых редакциях нарисован в эпизоде пляски героини, именно тогда она и привлекла внимание Демона. В редакции 1838 г. пляска героини исполнена страсти:

«И вот Тамара молодая

Берет свой бубен расписной;

$<\ldots>$

Кружа его над головой, Увлечена летучей пляской,

Она забыла мир земной;

Ее узорною повязкой

Играет ветер; как волна, Нескромной думою полна,

Грудь подымается высоко;

Уста бледнеют и дрожат,

И жадной страсти полон взгляд,

Как страсть палящий и глубокой!» (IV, 282-283).

Забвенье Тамарой земного мира в этом отрывке не означает сродство ее души с небом - доминантой образа становится страсть как нечто выходящее за пределы обычной человеческой жизни и имеющее неземное происхождение (как неземное происхождение имеет зло), но проявляющееся в плоти: «грудь подымается высоко», «уста бледнеют и дрожат». Лермонтов тонко подмечает развитие страсти - от мысли к выражению. Поэт образно представляет идею душевно-телесного единства человека: вначале Тамара «нескромной думою полна», а только затем - «и жадной страсти полон взгляд»; все эти характеристики определяют единство образа Тамары, который оказался притягателен для Демона.

Если обратиться к портрету Тамары в редакции 1839 г., то можно увидеть, что при создании ее образа преобладают другие тона: не женской страстности, но детской чистоты в пляске открывается ее младенческая душа: 
«Они поют - и бубен свой

Берет невеста молодая.

И вот она, одной рукой

Кружа его над головой,

То вдруг помчится легче птицы,

$<\ldots>$

И улыбается она,

Веселья детского полна.

Но луч луны, по влаге зыбкой

Слегка играющий порой,

Едва ль сравнится с той улыбкой,

Как жизнь, как молодость, живой» (IV, 187).

На смену бледнеющим дрожащим устам приходит детская улыбка, телесность Тамары представлена преображенной внутренним светом детской радости, ее сравнение с птицей способствует созданию впечатления о героини как о совершенном творении, превосходящем пределы земного притяжения. Как отмечает О. В. Сахарова, «ее телесная красота несет печать безгрешного райского человека, созданного по образу и подобию Божию» [Сахарова: 167]. Вероятно, именно идея тварного совершенства была заложена поэтом в основу образа Тамары, и именно она определила ее райскую красоту, декларируемую с небольшими изменениями по тексту Лермонтовым в обеих редакциях. В 8-й редакции:

«С тех пор, как мир лишился рая,

Клянусь, красавица такая

Под солнцем юга не цвела» (IV, 187).

Однако в редакции 1838 г. (6-й) красота неотделима от падшей женской природы, тогда как в редакции 1839 г. (8-й) красота молодой невесты является проявлением ее детской невинности и чистоты, близости ее души к Источнику всего сущего. В 8-й редакции, как пишет Б. Т. Удодов, «поэт окончательно освобождает образ Тамары от налета гаремновосточной чувственности, придает ее облику больше девической сдержанности, строгости и вместе с тем грации, детской непосредственности и гармонии» [Удодов: 371]. Изменяется и портрет мертвой Тамары, о чем, в частности, подробно 
пишет О. В. Миллер: если в 6-й редакции смысл улыбки Тамары «темен, как сама могила» $(\mathrm{IV}, 305)$ и «чувствуется явный намек на то, что Демон “наложил печать свою” на сердце Тамары» [Миллер: 174], то в 8-й редакции на ее лице только «печать смерти, никакого отзвука власти Демона» [Миллер: 175], в улыбке героини - «земле беззвучное прости» (IV, 213).

Вместе с изменением портрета Тамары меняется и ее судьба, достойная сожаления грешная душа изображается автором в объятиях ангела:

«В пространстве синего эфира

Один из ангелов святых

Летел на крыльях золотых,

И душу грешную от мира

Он нес в объятиях своих.

И сладкой речью упованья

Ее сомненья разгонял,

И след проступка и страданья

С нее слезами он смывал.

Издалека уж звуки рая

К ним доносилися — как вдруг...» (IV, 214-215).

Представляется вероятным, что при создании этого отрывка Лермонтов опирался на написанное им ранее стихотворение «Ангел» (1831):

«По небу полуночи ангел летел

И тихую песню он пел;

$<\ldots>$

Он пел о блаженстве безгрешных духов

Под кущами райских садов;

О Боге великом он пел, и хвала

Его непритворна была.

Он душу младую в объятиях нес

Для мира печали и слез;

И звук его песни в душе молодой

Остался - без слов, но живой.

И долго на свете томилась она,

Желанием чудным полна;

И звуков небес заменить не могли

Ей скучные песни земли» (I, 230). 
Связь «финального эпизода (ангел, несущий душу Тамары)» со стихотворением «Ангел» отмечал и А. М. Докусов [Докусов: 127]. Б. В. Удодов также совершенно справедливо полагал, что стихотворение «Ангел» чрезвычайно важно «для уяснения философского смысла “Демона"». Он подкреплял свои суждения тем, что в XI тетради, «в которую Лермонтов заносил свои произведения по мере их создания в течение всего второго полугодия 1831 г.», находится черновой вариант поэмы «Ангел смерти», а также «заметка для памяти о замысле "сатирической поэмы: приключения демона”» [Удодов: 311]. Анализируя 2-ю редакцию поэмы «Демон», В. Н. Аношкина писала о том, что Лермонтов был увлечен образом ангела и «в том же 1831 г. он создал шедевр трогательного и искреннего восхищения святостью - стихотворение “Ангел”» [Аношкина, 2014: 115].

В 8-й редакции стих «Он душу младую в объятиях нес...» из стихотворения «Ангел» перерабатываются в стихи: «И душу грешную от мира / Он нес в объятиях своих»; «звук его <ангела> песни», «звуки небес» преобразуются в «звуки рая». Образ души в объятиях ангела, звуки рая, а также мотив слез, связанный с грешным пребыванием на земле, сближают эти два поэтических шедевра, но, если в «Ангеле» вектор движения - от Неба к земле, то в отрывке из «Демона» - от земли к Небу. Сближению образного строя стихотворения и отрывка из поэмы также помогает портрет Тамары из редакции 1839 г. (8-й) до ее проступка: пляшущая героиня уподобляется ребенку, она «веселья детского полна», то есть ее душа сродни «душе младой» из стихотворения «Ангел». Лермонтов не включил это произведение в свое первое собрание стихотворений: вероятно, причины состояли в том, что оно уже тогда мыслилось поэтом как часть бо́льшего замысла.

Хранящиеся в Отделе рукописей Российской государственной библиотеки (ОР РГБ) беловые автографы стихотворений «Когда волнуется желтеющая нива...» и «Ангел» написаны на оборотах одного листа (Ф. 500 (Лермонтов). К. 1. Ед. хр. 3. Л. 1-1 об.). Возможно, что одной из причин размещения поэтом рядом этих двух произведений, разделенных между собой семью годами, являются его раздумья о новой редакции «Демона». 
Редакция «Демона» 1838 г. (6-я) не имеет цельности, она отличается художественной ломкостью. В ней уже наметился перелом, связанный с идеей вскрытия лукавства врага рода человеческого и ярко отразившийся в песне Демона, но еще не оформилась идея всесильной Божьей милости и любви к человеку, что нашло свое воплощение в редакции 1839 г., которая и явилась первой публикацией поэмы. Именно редакция 1839 г. отражает ключевые позиции мировоззрения Лермонтова, имеющего в своей основе духовный опыт, ясно запечатленный в стихотворении «Когда волнуется желтеющая нива...». Осмысление поэтом этого опыта определило его понимание сути мироустройства, в котором божественное всеприсутствие противопоставляется условности бытия и ограниченности власти демона, и именно этот опыт способствовал кардинальному изменению развязки в окончательной редакции поэмы «Демон».

\section{Примечания}

1 См., напр.: [Аничков], [Шувалов], [Эйхенбаум], [Любимова-Дороватовская], [Михайлова], [Гиреев], [От редакции], [Максимов], [Найдич], [Удодов], [Вацуро].

2 Лермонтов М. Ю. Демон. Берлин: F. Schneider \& C ${ }^{0}, 1856.57$ c.

3 Лермонтов М. Ю. Демон. Восточная повесть, сочиненная Михаилом Юрьевичем Лермонтовым. Карлсруэ: В Придворной Типографии B. Гаспера, $1856.58 \mathrm{c}$.

4 Лермонтов М. Ю. Сочинения: в 6 т. М.; Л.: Изд-во АН СССР, 1955-1957. Т. 4. Поэмы, 1835-1841. 1955. С. 289. Далее ссылки на это издание приводятся в тексте статьи с указанием тома (римской цифрой) и страницы в круглых скобках.

5 Новалис. Гимны к ночи / пер. с нем. В. Микушевича. М.: Энигма, 1996. C. 145 .

\section{Список литературы}

1. Аношкина В. Н. «Демон» // М. Ю. Лермонтов. Энциклопедический словарь / гл. ред. и сост. И. А. Киселева. - М.: Индрик, 2014. - С. 114-118.

2. Аничков Е. В. Методологические замечания о тексте «Демона». - СПб.: тип. Акад. наук, 1914. - [2], 81 с.

3. Вацуро В. Э. К цензурной истории «Демона» // М. Ю. Лермонтов: Исследования и материалы. - Л.: Наука, 1979. - С. 410-414.

4. Гаспаров М. М. «Когда волнуется желтеющая нива...» Лермонтов и Ламартин // Гаспаров М. М. О русской поэзии. Анализы. Интерпретации. Характеристики. - СПб.: Азбука, 2001. - С. 43-55. 
5. Гиреев Д. А. Поэма М. Ю. Лермонтова «Демон»: творческая история и текстологический анализ. - Орджоникидзе: Северо-Осетинское книжное изд-во, 1958. - 206 с.

6. Докусов А. М. Поэма М. Ю. Лермонтова «Демон» (К вопросу об идейной концепции и основном тексте поэмы) // Русская литература. - 1960. № 4. - С. 111-129.

7. Захаров В. Н. «Смелость изобретения» в романе М. Ю. Лермонтова «Герой нашего времени» // Проблемы исторической поэтики. - 2014. № 12. - C. 18-33 [Электронный ресурс]. - URL: http://poetica.pro/files/ redaktor_pdf/1429705931.pdf (15.01.2019). DOI: 10.15393/j9.art.2014.729

8. Иванова Т. А. Юность Лермонтова. - М.: Советский писатель, 1957. $357 \mathrm{c}$.

9. Киселева И. А. Онтология стихии в художественном мире М. Ю. Лермонтова // Вестник Московского государственного областного университета. Серия: Философские науки. - 2011. — № 4. - С. 74-78.

10. Киселева И. А. О познавательно-ценностном подходе к творчеству М. Ю. Лермонтова: телеология текста // Вестник Московского государственного областного университета. Серия: Русская филология. 2013. — № 6. - С. 82-87.

11. Киселева И. А. Творчество М. Ю. Лермонтова как религиозно-философская система. - М.: ИИУ МГОУ, 2017. - 178 с.

12. Любимова-Дороватовская В. С. Списки поэмы М. Ю. Лермонтова «Демон»: (по материалам Отдела рукописей) // М. Ю. Лермонтов: статьи и материалы. - М.: Гос. соц.-эконом. изд-во «Соцэкгиз», 1939. - С. 74-82.

13. Миллер О. В. К истории изучения поэмы М. Ю. Лермонтова «Демон»: полемические заметки // Stephanos. — 2015. — № 5 (13). - С. 171-176.

14. Михайлова А. Последняя редакция «Демона» // Литературное наследство. - М.: Изд-во АН СССР, 1948. - Т. 45-46. - С. 11-22.

15. Найдич Э. Э. Последняя редакция «Демона» // Русская литература. 1971. — № 1. - С. 75-78.

16. Максимов Д. Об изучении мировоззрения и творческой системы Лермонтова // Русская литература. - 1964. - № 3. - С. 9.

17. От редакции. Еще раз о недостатках издания сочинений Лермонтова // Вопросы литературы. - 1958. - С. 131-142.

18. Роднянская И. Б. Демон ускользающий // Движение литературы. - М.: Языки славянских культур, 2006. - Т. 1. - С. 63-90.

19. Сахарова О. В. Ангелоподобный образ княжны Тамары в поэме М. Ю. Лермонтова «Демон» // Материалы XII Международного форума. Липецкий государственный педагогический университет имени П. П. Семенова-Тян-Шанского. - 2017. - С. 167-171.

20. Удодов Б. В. М. Ю. Лермонтов. Художественная индивидуальность и творческие процессы. - Воронеж: Изд-во Воронежского университета, 1973. - 702 c. 
21. Шувалов С. В. К вопросу о тексте последней редакции поэмы Лермонтова «Демон» (По поводу академического издания под ред. Д. И. Абрамовича) // Беседы: сб. Общества истории литературы в Москве. - М.: Печатня А. И. Снегиревой, 1915. - С. 16-26.

22. Эйхенбаум Б. М. Поэмы и повести в стихах: комментарии и варианты // Лермонтов М. Ю. Полн. собр. соч.: в 5 т. / под ред. Б. М. Эйхенбаума. М.; Л.: Academia, 1935. - Т. 3. - С. 628-658.

Irina A. Kiseleva

Moscow State Regional University (Moscow, Russian Federation)

79099227849@yandex.ru

\section{On the Semantic Integrity of the Definitive Text of the Poem “Demon" by M. Yu. Lermontov (1839)}

Abstract. The subject of the study resides in certain aspects of a creative history of Lermontov's poem "Demon" in their accordance with the whole idea of the author. The emphasis of the article is placed on Demon's song "as soon as the night with veil her...", Tamara's portrait given in the 6th and the 8th editions, an episode of salvation of her soul. The poem "When the flavescent fields swing in the wind..." is seen as a contrasting allusion to the seductive song of the Demon. God's all-presence in the poem is contrasted to the conformity and limitations of existence and the demon's promises. The comparison of the Demon's song with the poem allows revealing an artistic and conceptual discrepancy between the editions of 1838 (the 6th) and of 1839 (the 8th). The Demon's song appeared in the 6th edition of the poem made it necessary to change the ending of the plot, which was proposed in the 8th edition. As a result, the change of the ending of the plot conditioned the essencial editing of the portrait of Tamara in the 8th edition compared to that one in the 6th edition. The passion of the character was replaced by the image of an infant soul the beauty of which is seen through the earthly image of Tamara, as an example of the created perfection. The poem of M. Yu. Lermontov "Angel” (1831) used for the analysis of the Demon, the periphrasis of which is most clearly seen in the ending of the 8th edition, is considered as a part of the poem's conception. It is concluded that the 8th edition reflects in a comprehensive and consistent way the worldview of M. Yu. Lermontov, his belief in the omnibenevolecence of the Creator and the Supreme intelligence of the universe.

Keywords: Lermontov, "The Demon", "The Angel", editions, textual study, architectonics of text, spiritual reality, Tamara's portrait

About the author: Kiseleva Irina A. - Doctor of Philology, Professor, Head of the Department of Russian Classical Literature, Moscow State Regional University (ul. Fridrikha Engel'sa 21/3, Moscow, 105005, Russian Federation)

Received: January 15, 2019

Date of publication: October 18, 2019 
For citation: Kiseleva I. A. On the Semantic Integrity of the Definitive Text of the Poem "Demon" by M. Yu. Lermontov (1839). In: Problemy istoricheskoy poetiki [The Problems of Historical Poetics], 2019, vol. 17, no. 4, pp. 91-106. DOI: 10.15393/j9.art.2019.6422 (In Russ.)

\section{References}

1. Anoshkina V. N. “The Demon”. In: M. Yu. Lermontov: entsiklopedicheskiy slovar' [M. Yu. Lermontov: An Encyclopaedic Dictionary]. Moscow, Indrik Publ., 2014, pp. 114-118. (In Russ.)

2. Anichkov E. V. Metodologicheskie zamechaniya o tekste "Demona» [Methodological Notes on the Text of "The Demon"]. St. Petersburg, tipografiya Akademii nauk Publ., 1914. 81 p. (In Russ.)

3. Vatsuro V. E. On the Censorial History of "The Demon". In: M. Yu. Lermontov: Issledovaniya i materialy [M. Yu. Lermontov: Researches and Materials]. Leningrad, Nauka Publ., 1979, pp. 410-414. (In Russ.)

4. Gasparov M. M. "When the Flavescent Fields Swing in the Wind..." Lermontov and Lamartine. In: Gasparov M. M. O russkoy poezii. Analizy. Interpretatsii. Kharakteristiki [Gasparov M. M. About Russian Poetry. Analyses. Interpretations. Characteristics]. St. Petersburg, Azbuka Publ., 2001, pp. 43-55. (In Russ.)

5. Gireev D. A. Poema M. Yu. Lermontova "Demon»: tvorcheskaya istoriya i tekstologicheskiy analiz [Lermontov's Poem "The Demon": Creative History and Textual Analysis]. Ordzhonikidze, Severo-Osetinskoe knizhnoe izdatel'stvo Publ., 1958. 206 p. (In Russ.)

6. Dokusov A. M. M. Yu. Lermontov's Poem “The Demon” (On the Ideological Concept and Main Text of the Poem). In: Russkaya literatura, 1960, no. 4, pp. 111-129. (In Russ.)

7. Zakharov V. N. "Boldness of Invention" in Lermontov's a Hero of Our Time. In: Problemy istoricheskoy poetiki [The Problems of Historical Poetics], 2014, no. 12, pp. 18-33. Available at: http://poetica.pro/files/redaktor_pdf/1429705931. pdf (accessed on January 15, 2019). DOI: 10.15393/j9.art.2014.729 (In Russ.)

8. Ivanova T. A. Yunost' Lermontova [Lermontov's Youth]. Moscow, Sovetskiy pisatel' Publ., 1957. 357 p. (In Russ.)

9. Kiseleva I. A. The Ontology of Elements in the Artistic World of M. Yu. Lermontov. In: Vestnik Moskovskogo gosudarstvennogo oblastnogo universiteta. Seriya: Filosofskie nauki [Bulletin of the Moscow Region State University. Series: Philosophy], 2011, no. 4, pp. 74-78. (In Russ.)

10. Kiseleva I. A. On a Cognitive and Value-based Approach to the Works of M. Yu. Lermontov: Teleology of Text. In: Vestnik Moskovskogo gosudarstvennogo oblastnogo universiteta. Seriya: Russkaya filologiya [Bulletin of the Moscow Region State University. Series: Russian Philology], 2013, no. 6, pp. 82-87. (In Russ.) 
11. Kiseleva I. A. Tvorchestvo M. Yu. Lermontova kak religiozno-filosofskaya sistema [The Works of M. Yu. Lermontov as a Religious-Philosophical System]. Moscow, Informatsionno-izdatel'skoe upravlenie of MRSU Publ., 2017. 178 p. (In Russ.)

12.Lyubimova-Dorovatovskaya B. C. The Lists of M. Yu. Lermontov's Poem "The Demon": (on the Materials of the Department of Manuscripts). In: M. Yu. Lermontov: stat'i i materialy [M. Yu. Lermontov: Articles and Materials]. Moscow, Sotsekgiz Publ., 1939, pp. 74-82. (In Russ.)

13. Miller O. V. On the History of the Studying of M. Yu. Lermontov's Poem “The Demon": Polemic Notes. In: Stephanos, 2015, no. 5 (13), pp. 171-176. (In Russ.)

14. Mikhaylova A. The Last Edition of "The Demon”. In: Literaturnoe nasledstvo [Literary Heritage]. Moscow, Academy of Sciences of the USSR Publ., 1948, vol. 45-46, pp. 11-22. (In Russ.)

15. Naydich E. E. The Last Edition of “The Demon”. In: Russkaya literatura, 1971, no. 1, pp. 75-78. (In Russ.)

16. Maksimov D. About Studying of Lermontov's Worldview and Creative System. In: Russkaya literatura, 1964, no. 3, p. 9. (In Russ.)

17. An Editorial Note. Once Again About the Shortcomings of the Publication of Lermontov's Works. In: Voprosy literatury, 1958, pp. 131-142. (In Russ.)

18. Rodnyanskaya I. B. An Evanescent Demon. In: Dvizhenie literatury [The Movement of Literature]. Moscow, Yazyki slavyanskikh kul'tur Publ., 2006, vol. 1, pp. 63-90. (In Russ.)

19. Sakharova O. V. An Angel-like Image of Princess Tamara in M. Yu. Lermontov's Poem “The Demon”. In: Materialy XII Mezhdunarodnogo foruma. Lipetskiy gosudarstvennyy pedagogicheskiy universitet imeni P. P. Semenova-Tyan-Shanskogo [Proceedings of the 12th International Forum. Lipetsk State Pedagogical University Named after P. P. Semenov-Tyan-Shansky], 2017, pp. 167-171. (In Russ.)

20.Udodov B. V. M. Yu. Lermontov. Khudozhestvennaya individual'nost' itvorcheskie protsessy [M. Yu. Lermontov. Artistic Individuality and Creative Processes]. Voronezh, Voronezh State University Publ., 1973. 702 p. (In Russ.)

21. Shuvalov S. V. On the Text of the Last Edition of Lermontov's Poem "The Demon" (About the Academic Publication Edited by D. I. Abramovich). In: Besedy: sbornik Obshchestva istorii literatury v Moskve [Conversations: the Collection of the Society of the History of Literature in Moscow]. Moscow, Pechatnya A. I. Snegirevoy Publ., 1915, pp. 16-26. (In Russ.)

22. Eykhenbaum B. M. Poems and Novels in Verses: Comments and Variants. In: Lermontov M. Yu. Polnoe sobranie sochineniy v 5 tomakh [Lermontov M. Yu. The Complete Works: in 5 Vols]. Moscow, Leningrad, Academia Publ., 1935, vol. 3, pp. 628-658. (In Russ.) 